${ }^{1}$ Department of Oral Diagnosis, Division of Oral Radiology, Piracicaba Dental School, University of Campinas (UNICAMP), Piracicaba, São Paulo, Brazil.

${ }^{2}$ Pediatric Dentistry Department, Piracicaba Dental School, University of Campinas (UNICAMP), Av. Limeira, 901, 13414-903, Piracicaba, São Paulo, Brazil.
Corresponding author: Deborah Queiroz Freitas University of Campinas. Piracicaba Dental School, Department of Oral Diagnosis. Av. Limeira, 901, Zip Code 13414-903, Piracicaba, São Paulo, Brazil.

Phone/Fax: +55 19 2106-5327.

E-mail: deborahq@unicamp.br

(iD) https://orcid.org/0000-0002-1425-5966

Received: May 03, 2019

Accepted: August 302019

\section{Efficacy of digital} radiographic systems in the quality assessment of intracanal materials used for primary teeth

\author{
Guilherme Fantini Ferreira' ${ }^{1}$, Larissa Pereira Lagos \\ de Meloํ․, Mariana Rocha Nadaes ${ }^{1}$, Fernanda Maria \\ Mazoni Reis' ${ }^{2}$, Fernanda Miori Pascon², Deborah \\ Queiroz Freitas ${ }^{1, *}$
}

Aim: To evaluate the performance of three digital radiographic systems in the analysis of root canal filling quality using different intracanal materials for primary teeth. Methods: Twenty-five bovine teeth were divided into 5 groups: Calen ${ }^{\circledR}$ combined with iodoform; Calen ${ }^{\circledR}$ combined with zinc oxide; zinc oxide and eugenol; UltraCal ${ }^{\circledR} X S$, and $2 \%$ chlorhexidine combined with $\mathrm{Ca}(\mathrm{OH})_{2}+$ zinc oxide. Periapical radiographs were obtained with the VistaScan, Express, and SnapShot systems. The quality of the images was evaluated objectively (radiopacity) and subjectively (apical sealing and filling homogeneity). As the reference standard, the teeth were scanned with a micro-CT device. Results: Radiopacity differed among the radiographic systems and materials tested. In general, the greatest difference was observed between the Express and VistaScan systems; Calen ${ }^{\circledR}$ combined with iodoform resulted in the highest radiopacity. The radiographic systems did not differ in terms of homogeneity. However, Calen ${ }^{\circledR}$ combined with iodoform differed from the other materials and exhibited the best results. Regarding apical sealing, the SnapShot system and Calen ${ }^{\circledR}$ combined with zinc oxide provided the best results. Conclusion: Direct digital systems show better performance in evaluating the quality of endodontic treatment in primary teeth and should be preferred for this purpose.

Keywords: Radiography, dental, digital. Tooth, deciduous. Root canal filling materials. 


\section{Introduction}

Conservative management is currently the focus of dentistry, notably in pediatric dentistry, which consists of preserving the primary dentition in the dental arch until the period of physiological exfoliation' ${ }^{1}$. Endodontic treatment can prevent the extraction of those teeth if it is correctly indicated. Periapical radiography is first indicated to evaluate the quality of these treatments, as well as the periapical status of endodontically treated teeth, since it enables visualization of the tooth and its relationships with adjacent tissues $^{2}$. Nowadays, digital radiographic systems using either direct (solid complementary metal-oxide-semiconductor sensors - CMOS) or semidirect acquisition methods (photostimulable phosphor plates - PSP) 3 are applied in clinical practice. These systems mainly differ in their acquisition process and spatial and contrast resolution.

The influence of different characteristics of digital receptors has been studied for some diagnostic tasks, such the evaluation of caries lesions ${ }^{4,5}$, periapical lesions $s^{6,7}$, root fractures ${ }^{8,9}$, and fractured endodontic instruments ${ }^{10}$. However, we found no studies investigating the effect of these systems on the quality assessment of root canal filling. It is therefore important to establish whether different radiographic systems show diverse performance in evaluating endodontic treatment. This would allow dental professionals to use more adequate systems for this type of procedure, resulting in an accurate and reliable diagnosis, treatment and follow-up. An adequate analysis of radiographic images is necessary for diagnostic purposes and to ensure the success of endodontic treatment in primary teeth and of their follow-up.

Adequate radiographic images are important for assessing endodontic treatment quality. Since periapical radiography is the first choice for this purpose and considering the wide range of digital systems available for clinical use and the lack of studies about the topic, our aim was to investigate the influence of three digital radiographic systems using CMOS and PSP technologies on the evaluation of root canal filling quality when different materials designed for the treatment of primary teeth were used. The null hypotheses stated that there would be no differences among the different digital systems or materials.

\section{MATERIAL AND METHODS}

\section{Selection and preparation of the samples}

Twenty-five bovine primary teeth were selected. Their crowns were removed and a 22-mm length of the root was kept in order to standardize the size of the roots. The length was determined with the aid of an endodontic ruler and confirmed with a digital caliper. The roots were randomly divided into 5 different groups according to the filling material:

- Calen $^{\circledR}$ (S.S. White, batch \#0080713) combined with iodoform (Biodinâmica, batch \#59813) (Ca + Io);

- $\quad$ Calen ${ }^{\circledR}$ combined with zinc oxide (Biodinâmica, batch \#38513) (Ca + ZnO);

- $\quad$ zinc oxide and eugenol (Biodinâmica, batch \#48013) (ZOE);

- $\quad$ UltraCal ${ }^{\circledR X S}$ (UltraDent, batch \#B7W8P) (UltraCal); 
- chlorhexidine digluconate 2\% (Essencial Pharma, batch \#1009364) combined with calcium hydroxide $\left[\mathrm{Ca}(\mathrm{OH})_{2}\right]$ (Biodinâmica, batch \#114113) + ZnO (chlorhexidine).

The chemical-mechanical preparation was carried out by the same operator using the step-back technique with $1^{\text {st }}$ series files K (\#15 to \#40) (Maillefer, Tulsa, OK, USA) and 0.5\% sodium hypochlorite ( $\mathrm{NaOCl}$ ) (Biodinâmica, Ibiporã, PR, Brazil) + Endo-PTC (urea peroxide, polysorbate 80 and polyethylene glycol) (Biodinâmica, Ibiporã, PR, Brazil) after every file size exchange. The combination of $\mathrm{NaOCl}$ and Endo-PTC is frequently used in the endodontic treatment of primary teeth. The peroxides react chemically, releasing large amounts of nascent oxygen that explains their bactericidal activity ${ }^{11,12}$ Circular movements were performed and $2.5 \mathrm{ml}$ of $0.5 \% \mathrm{NaOCl}$ was used for irrigation. The opening of the apical foramen was standardized with a \# $40 \mathrm{~K}$-file so the canal had a cylindrical shape. Finally, the canals were irrigated with $5 \mathrm{ml}$ of $0.89 \%$ saline solution and dried with an absorbent paper cone.

The filling materials were then introduced into the root canals with a \# 20 endodontic file (Maillefer, Tulsa, OK, USA), except for the UltraCa ${ }^{\circledR} X S$ group, in which a syringe provided by the manufacturer was used. Vertical condensation technique was employed by vertical compression was carried out with cotton balls and the root canal was sealed in the cervical region with a resin composite restoration (Z250 XT, 3M ESPE, Saint Paul, MN, USA).

\section{Radiographic images}

After root canal filling, digital radiographs (Figure 1) were obtained with the following devices:

- $\quad$ phosphor plate, 2 sizes, of the Express digital system (Instrumentarium Imaging,

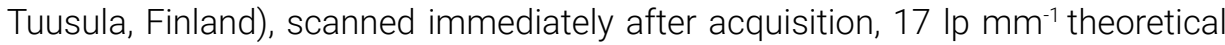
spatial resolution according to the manufacturer, and CliniView software (Instrumentarium Imaging);

- phosphor plate, 2 sizes, of the VistaScan digital system (Dürr Dental, Bietigheim-Bissingen, Germany), scanned immediately after acquisition, $25.6 \mathrm{Ip} \mathrm{mm}^{-1}$ theoretical spatial resolution according to the manufacturer, and DBSWIN software (Dürr Dental);

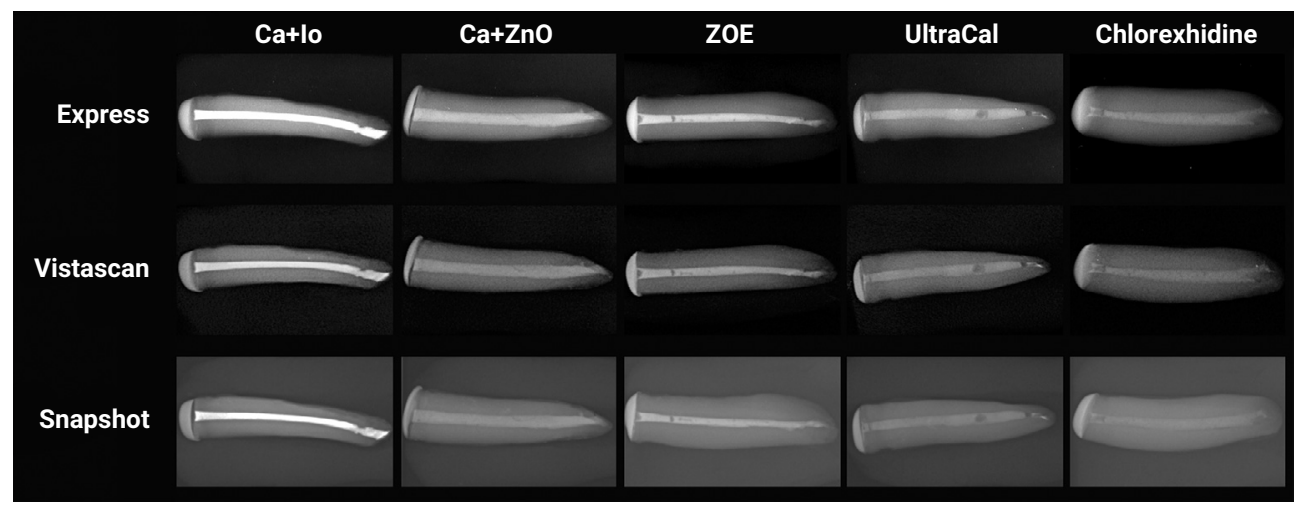

Figure 1. Cropped periapical radiographs of teeth with different intracanal materials obtained with the radiographic systems studied. 
- $\quad$ solid CMOS sensor, 1 size, of the SnapShot digital system (Instrumentarium Imaging, Tuusula, Finland), $26.3 \mathrm{Ip} \mathrm{mm}^{-1}$ theoretical spatial resolution according to the manufacturer, and CliniView software (Instrumentarium Imaging).

The radiographic exposures were obtained using a Focus $X$-ray device (Instrumentarium Dental, Tuusula, Finland) operating at $70 \mathrm{kV}$ and $7 \mathrm{~mA}$, with an exposure time of $0.1 \mathrm{~s}$ for the VistaScan and Express systems and of $0.063 \mathrm{~s}$ for the SnapShot system. The exposure times were established in a pilot study.

For image acquisition, each tooth was placed parallel to the radiographic receptor and the radiation was set perpendicular to both, with a focus-receiver distance of $30 \mathrm{~cm}$. In addition, an aluminum step wedge with uniform incremental steps from 1 to $10 \mathrm{~mm}$ was placed on the receptor adjacent to the tooth.

\section{Evaluation of the radiographic images}

The images were evaluated objectively by determining the mean gray values of the intracanal materials and aluminum wedge, as well as subjectively through the scores assigned by the examiners to the filling quality. In both analyses, the examiners were blinded to the digital system and material used. The examiners were previously calibrated and performed the evaluation on a 24.1" LCD monitor with a resolution of 1920x1200 pixels (MDCR-2124, Barco, Kortrijk, Belgium) in a dimly lit and quiet environment.

Objective analysis was carried out by an experienced examiner. For this purpose, the images were exported in TIFF format for analysis with the ImageJ 1.49 software (National Institutes of Health, Bethesda, Maryland, USA). Regions of interest (ROI) of 0.4 $\times 0.4 \mathrm{~mm}$ were determined in coronal, middle and apical root thirds of the filling material, as well as in the second, third and fourth step of the aluminum wedge (Figure 2). After determination of the ROls, the gray levels were obtained. In the ImageJ program, value 0 assigns the color black and value 255 the color white. The final radiopacity of each material was calculated by averaging the values of the three thirds. Additionally, the values obtained between the third and second steps and between the fourth and third steps were subtracted and the mean was taken for expressing the average contrast that each radiographic system exhibited for the same aluminum wedge.

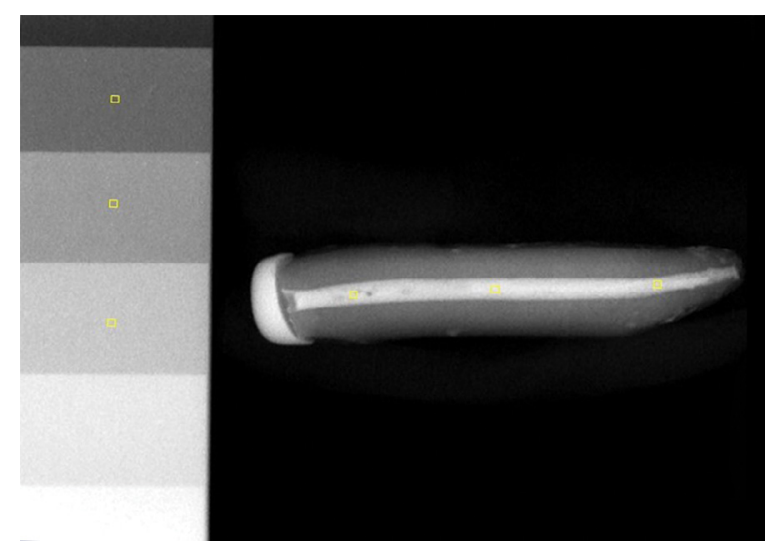

Figure 2. Regions of interest (ROI) in the coronal, middle and apical thirds of roots filled with the intracanal material, and in the second, third and fourth step of the aluminum wedge. 
For subjective evaluation, two oral and maxillofacial radiologists with over 5 years of experience in the evaluation of digital radiographic images assessed the images together and reached a consensus. The examiners were allowed to adjust brightness and contrast and to use the zoom tool freely. For each image, the examiners classified the homogeneity of the filling on a two-point scale: $1=$ adequate, or 2 = inadequate. Score 1 was attributed if the root canal filling showed no empty spaces, no failure in internal adaptation, and no bubbles. If these occurred, score 2 was attributed. The scores were recorded separately for each third of the root. Regarding apical sealing, score 1 (adequate) was attributed when the root canal was sealed and the material was 0 to $2 \mathrm{~mm}$ from the radiographic apex. If the apical limit of the filling was more than $2 \mathrm{~mm}$ from the radiographic apex and/or the material did not seal the canal, score 2 (inadequate) was attributed (Figure 3). After 30 days, the subjective evaluation was repeated in $40 \%$ of the sample to obtain the intra-examiner agreement.

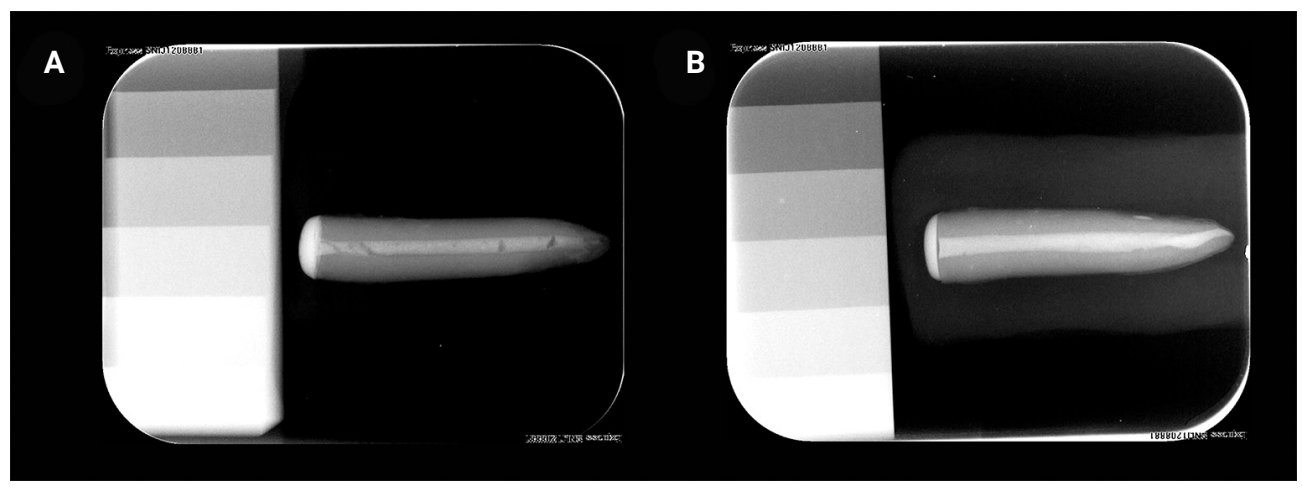

Figure 3. Examples of $(\mathrm{A})$ inadequate score $\left(2 \%\right.$ chlorhexidine digluconate combined with $\left.\mathrm{Ca}(\mathrm{OH})_{2}+\mathrm{ZnO}\right)$ and $(B)$ adequate score (Calen ${ }^{\circledR}$ combined with zinc oxide) for the two parameters evaluated (sealing and homogeneity).

\section{Reference standard}

As reference standard for subjective analysis, the teeth were scanned with a micro-computed tomography (CT) device (SkyScan 1178; Bruker, Kontich, Belgium). Scanning was performed at a voltage of $65 \mathrm{kV}$, current of $615 \mu \mathrm{A}$, and voxel size of $8.46 \mu \mathrm{m}$. The images were reconstructed with the NRecon software (v1.6.4.8, Bruker, Kontich, Belgium), and the DataViewer software (v1.5.1.2, Bruker, Kontich, Belgium) was used for the analysis. In this analysis, one observer determined if the endodontic filling material was homogeneously distributed inside the root canal or if it contained bubbles, as well as if the apex was sealed.

\section{Data analysis}

The SPSS 22.0 program (SPSS, Inc., Chicago, Illinois, USA) was used for statistical analysis, adopting a significance level of $5 \%$. Normality of the data was tested using the Shapiro-Wilk test. 
The gray values of the material's radiopacity and those corresponding to the contrast of the aluminum wedge obtained in the objective analysis were compared by analysis of variance (two-way ANOVA: digital systems and filling materials). The Tukey test was used for post hoc analysis. The null hypothesis considered the absence of significant differences among the different digital systems or materials. The scores attributed in the subjective evaluation were compared using the Friedman test. The null hypothesis considered the absence of influence of the different digital systems, different materials or different thirds of the root on the evaluation. Additionally, the kappa test was used to assess intra-examiner agreement.

\section{RESULTS}

The mean radiopacity values of the materials are presented in Table 1. The systems differed from each other $(p<0.005)$ and the greatest difference was observed between the Express and VistaScan systems. A difference was also observed between some materials being $\mathrm{Ca}+\mathrm{lo}$ different from the other materials, with $\mathrm{Ca}+\mathrm{lo}$ exhibiting the highest radiopacity. Table 2 shows the mean contrast of each radiographic system for the aluminum wedge. All systems differed from each other $(p<0.005)$ and the Express system exhibited the highest contrast.

Table 1. Mean and standard deviation radioapacity values of the filling materials in the radiographic systems studied

\begin{tabular}{lccc}
\hline Material & \multicolumn{1}{c}{ Express } & VistaScan & \multicolumn{1}{c}{ Snapshot } \\
\hline $\mathrm{Ca}+\mathrm{lo}$ & $254.05(2.13) \mathrm{Aa}$ & $207.94(5.35) \mathrm{Ba}$ & $241.25(10.71) \mathrm{Aa}$ \\
\hline $\mathrm{Ca}+\mathrm{ZnO}$ & $207.17(10.32) \mathrm{Abc}$ & $146.20(6.44) \mathrm{Bb}$ & $143.75(6.97) \mathrm{Bbc}$ \\
\hline $\mathrm{ZOE}$ & $209.84(13.23) \mathrm{Ab}$ & $156.42(7.69) \mathrm{Bb}$ & $162.48(7.96) \mathrm{Bb}$ \\
\hline UltraCal & $182.21(25.64) \mathrm{Ac}$ & $130.98(12.28) \mathrm{Bbc}$ & $128.02(15.84) \mathrm{Bc}$ \\
\hline Chlorhexidine & $143.66(17.32) \mathrm{Ad}$ & $116.65(6.43) \mathrm{Bc}$ & $133.29(2.19) \mathrm{Ac}$ \\
\hline
\end{tabular}

$\mathrm{Ca}+\mathrm{lo}-$ Calen $^{\circledR}+$ iodoform

$\mathrm{Ca}+\mathrm{ZnO}-$ Calen $^{\circledR}+$ zinc oxide

ZOE - Zinc oxide and eugenol

UltraCal - UltraCal ${ }^{\otimes X S}$

Chlorhexidine - Chlorhexidine digluconate $2 \%+$ calcium hydroxide + zinc oxide

Different uppercase letters indicate differences between the systems (columns) and lowercase letters indicate differences between the materials (rows).

Table 2. Mean and standard deviation (SD) contrast of aluminum scale in the radiographic systems studied

\begin{tabular}{ll}
\hline System & \multicolumn{1}{c}{ Mean (SD) } \\
\hline Express & $48.77(2.53)$ A \\
\hline VistaScan & $21.34(1.83)$ B \\
\hline SnapShot & $16.87(1.41)$ C \\
\hline
\end{tabular}

Different letters indicate statistical differences. 
The results of subjective evaluation and of the reference standard are illustrated in Tables 3 and 4. Regarding homogeneity (Table 3), no differences were observed among the radiographic systems $(p=0.573)$. However, the root third and the material influenced homogeneity ( $p=0.0001$ and 0.0007 , respectively). In general, the apical third received more inadequate scores. Moreover, $\mathrm{Ca}+$ lo differed from the other materials and showed the best results, receiving more adequate scores, whereas chlorhexidine and UltraCal provided the worst results.

Table 3. Adequate homogeneity scores according to the filling materials, radiographic systems and reference standard (\%)

\begin{tabular}{|c|c|c|c|c|c|c|c|c|c|c|c|c|c|c|c|}
\hline Material* & \multicolumn{3}{|c|}{$\mathrm{Ca}+\mathrm{Io}(\mathrm{A})$} & \multicolumn{3}{|c|}{ Calen + ZnO (B) } & \multicolumn{3}{|c|}{ ZOE (B) } & \multicolumn{3}{|c|}{ UltraCal (C) } & \multicolumn{3}{|c|}{ Chlorexhidine (C) } \\
\hline Third** & & $\mathrm{n}(\%)$ & & & n (\%) & & & $\mathrm{n}(\%)$ & & & $\mathrm{n}(\%)$ & & & n (\%) & \\
\hline System ${ }^{\star \star \star}$ & Cervical & Middle & Apical & Cervical & Middle & Apical & Cervical & Middle & Apical & Cervical & Middle & Apical & Cervical & Middle & Apical \\
\hline Express & $\begin{array}{c}25 \\
(100)\end{array}$ & $\begin{array}{c}25 \\
(100)\end{array}$ & $\begin{array}{c}25 \\
(100)\end{array}$ & $\begin{array}{c}25 \\
(100)\end{array}$ & $\begin{array}{c}0 \\
(0)\end{array}$ & $\begin{array}{c}0 \\
(0)\end{array}$ & $\begin{array}{c}20 \\
(80)\end{array}$ & $\begin{array}{c}15 \\
(60)\end{array}$ & $\begin{array}{c}0 \\
(0)\end{array}$ & $\begin{array}{c}0 \\
(0)\end{array}$ & $\begin{array}{c}4 \\
(20)\end{array}$ & $\begin{array}{c}0 \\
(0)\end{array}$ & $\begin{array}{c}10 \\
(40)\end{array}$ & $\begin{array}{c}0 \\
(0)\end{array}$ & $\begin{array}{c}0 \\
(0)\end{array}$ \\
\hline VistaScan & $\begin{array}{c}25 \\
(100)\end{array}$ & $\begin{array}{c}25 \\
(100)\end{array}$ & $\begin{array}{c}15 \\
(60)\end{array}$ & $\begin{array}{c}15 \\
(60)\end{array}$ & $\begin{array}{c}4 \\
(20)\end{array}$ & $\begin{array}{c}4 \\
(20)\end{array}$ & $\begin{array}{c}20 \\
(80)\end{array}$ & $\begin{array}{c}10 \\
(40)\end{array}$ & $\begin{array}{c}0 \\
(0)\end{array}$ & $\begin{array}{c}4 \\
(20)\end{array}$ & $\begin{array}{c}10 \\
(40)\end{array}$ & $\begin{array}{c}0 \\
(0)\end{array}$ & $\begin{array}{c}4 \\
(20)\end{array}$ & $\begin{array}{c}0 \\
(0)\end{array}$ & $\begin{array}{c}0 \\
(0)\end{array}$ \\
\hline Snapshot & $\begin{array}{c}20 \\
(80)\end{array}$ & $\begin{array}{c}25 \\
(100)\end{array}$ & $\begin{array}{c}15 \\
(60)\end{array}$ & $\begin{array}{c}20 \\
(80)\end{array}$ & $\begin{array}{c}4 \\
(20)\end{array}$ & $\begin{array}{c}0 \\
(0)\end{array}$ & $\begin{array}{c}15 \\
(60)\end{array}$ & $\begin{array}{c}4 \\
(20)\end{array}$ & $\begin{array}{c}0 \\
(0)\end{array}$ & $\begin{array}{c}0 \\
(0)\end{array}$ & $\begin{array}{c}4 \\
(20)\end{array}$ & $\begin{array}{c}0 \\
(0)\end{array}$ & $\begin{array}{c}10 \\
(40)\end{array}$ & $\begin{array}{c}0 \\
(0)\end{array}$ & $\begin{array}{c}4 \\
(20)\end{array}$ \\
\hline MicroCT & $\begin{array}{c}20 \\
(80)\end{array}$ & $\begin{array}{c}20 \\
(80)\end{array}$ & $\begin{array}{c}15 \\
(60)\end{array}$ & $\begin{array}{c}25 \\
(100)\end{array}$ & $\begin{array}{c}4 \\
(20)\end{array}$ & $\begin{array}{c}0 \\
(0)\end{array}$ & $\begin{array}{c}20 \\
(80)\end{array}$ & $\begin{array}{c}10 \\
(40)\end{array}$ & $\begin{array}{c}4 \\
(20)\end{array}$ & $\begin{array}{c}0 \\
(0)\end{array}$ & $\begin{array}{c}0 \\
(0)\end{array}$ & $\begin{array}{c}0 \\
(0)\end{array}$ & $\begin{array}{c}4 \\
(20)\end{array}$ & $\begin{array}{c}4 \\
(20)\end{array}$ & $\begin{array}{c}0 \\
(0)\end{array}$ \\
\hline
\end{tabular}

$\mathrm{Ca}+$ lo - Calen $^{\circledR}+$ iodoform

$\mathrm{Ca}+\mathrm{ZnO}-$ Calen $^{\circledR}+$ zinc oxide

ZOE - Zinc oxide and eugenol

UltraCal - UltraCal ${ }^{\oplus S}$

Chlorhexidine - Chlorhexidine digluconate $2 \%+$ calcium hydroxide + zinc oxide

* Some materials differed in the homogeneity evaluation ( $p=0.0007)$ - Difference indicated by the different letters between the parentheses.

** The thirds differed between themselves, regarding the homogeneity $(p=0.0001)$.

*** The radiographic systems did not differ between themselves in the homogeneity evaluation $(p=0.573)$.

Table 4. Adequate apical sealing scores according to the filling materials, radiographic systems and reference standard (\%)

\begin{tabular}{lccccc}
\hline Material* $^{*}$ & $\mathbf{C a}+$ lo (AB) & Calen + ZnO (A) & ZOE (AB) & UltraCal (B) & Chlorexhidine (B) \\
\hline System $^{\star *}$ & $\mathbf{n}(\%)$ & $\mathbf{n}(\%)$ & $\mathbf{n}(\%)$ & $\mathbf{n}(\%)$ & $\mathbf{n}(\%)$ \\
\hline Express (b) & $20(80)$ & $25(100)$ & $20(80)$ & $10(40)$ & $15(60)$ \\
\hline VistaScan (b) & $20(80)$ & $25(100)$ & $20(80)$ & $4(20)$ & $10(40)$ \\
\hline Snapshot (ab) & $15(60)$ & $20(80)$ & $20(80)$ & $10(40)$ & $10(40)$ \\
\hline MicroCT (a) & $15(60)$ & $20(80)$ & $15(60)$ & $0(0)$ & $4(20)$
\end{tabular}

$\mathrm{Ca}+\mathrm{lo}-$ Calen $^{\circledast}+$ iodoform

$\mathrm{Ca}+\mathrm{ZnO}-$ Calen $^{\circledR}+$ zinc oxide

ZOE - Zinc oxide and eugenol

UltraCal - UltraCal ${ }^{\circledR} X S$

Chlorhexidine - Chlorhexidine digluconate $2 \%+$ calcium hydroxide + zinc oxide

* Some materials differed in the apical sealing evaluation $(p=0.0133)$ - Difference indicated by the different uppercase letters between the parentheses in horizontal.

** Some systems differed in the apical sealing evaluation $(p=0.0127)$ - Difference indicated by the different lowercase letters between the parentheses in vertical. 
Regarding apical sealing (Table 4), some differences were observed among the radiographic systems $(p=0.0127)$. SnapShot was the only system that did not differ from the micro-CT scans (reference standard). In addition, some differences were found among the materials $(p=0.0133)$, with $\mathrm{Ca}+$ ZOE providing better results than UltraCal and chlorhexidine.

The intra-examiner agreement was excellent for both homogeneity and apical sealing (kappa $=0.954$ and 1.0 , respectively).

\section{DISCUSSION}

Current X-ray detectors usually show satisfactory performance in terms of spatial resolution, contrast, and exposure latitude in quantitative analyse ${ }^{13}$. However, in view of the variety of digital systems and their diverse performance in different diagnostic tasks, it is important to test the technologies (CMOS and PSP) for not yet studied tasks, such as root filling quality. In this respect, we found that one of the digital systems studied provided some improvement in the evaluation of apical sealing.

In radiographic images, one factor that influences on detail discernment is the spatial resolution of the X-ray detector, which refers to the size of the smallest possible feature that can be detected. In this respect, a higher spatial resolution seems to have some benefit in the evaluation of apical sealing since SnapShot permitted better analysis. The same radiographic system provided some improvement in the evaluation of fractured endodontic files and vertical root fractures in teeth with glass fiber posts ${ }^{9,10}$. These previous studies also attributed the better performance to the higher spatial resolution of the system.

It is important to note that the systems studied use different technologies, a fact that could also influence the results. However, they were controlled during the experiment. Regarding image acquisition, PSPs require scanning for imaging assessment. Therefore, a decrease in image quality may occur over time or secondary to exposure to ambient light through the electron decay of PSP' traps in higher energy states ${ }^{14}$. The VistaScan and Express systems (PSPs) are capable of producing high-quality images, even if they are manipulated in bright rooms. However, if these images are evaluated objectively, the result of incorrect handling can be quantified ${ }^{14}$. Nevertheless, PSPs spontaneously release captured electrons over time and attention must therefore be paid to the scanning process ${ }^{14}$. To avoid these biases, we exposed the plates to $X$-rays and scanned them immediately in a room with little light.

In addition to higher spatial resolution, the solid sensors (CMOS) produce a digital image immediately after radiation exposure. Therefore, the quality of the final image is not influenced by the external light. Moreover, in CMOS, the dexels of the receptors are separate from each other, so that each one is connected directly to a converter. This ensures the individualization of the voltage of the pixel transfer and, thus, individual evaluation.

Contrast resolution is the ability to distinguish between differences in intensity in an image and depends on the bit depth. Images with 8-bit depth can provide 256 shades of gray per pixel. A high contrast resolution increases the availability of shades of gray in an image. Theoretically, this could improve diagnosis with more 
shades of gray in image until a limit considering the ability that the human eye can see and the contemporary computer monitors can support ${ }^{15}$. However, our results showed that spatial resolution seems to be more important than contrast resolution, as SnapShot exhibited better performance but lower contrast resolution when the aluminum wedge was evaluated.

In addition to the influence of radiographic systems, the different intracanal materials used for the endodontic treatment of primary teeth could interfere with the evaluation of root canal filling quality. However, the filling materials must meet some criteria for use in the root filling of primary teeth, such as being antibacterial, being resorbable at the same proportion as the root of the tooth, being biocompatible, easily filling the channels, adhering to the walls, not causing discoloration of the tooth, and being radiopaque ${ }^{16}$. Although some of these characteristics were not tested in the present study, radiopacity is an important feature to verify the full extent of the material and the presence of faults and voids and was therefore evaluated in the study.

Nowadays, several types of filling materials for primary teeth are available, with materials containing zinc oxide, $\mathrm{Ca}(\mathrm{OH})_{2}$ and iodoform being commonly used ${ }^{17,18}$. Zinc oxide and eugenol has been recommended by the American Academy of Pediatric Dentistry (AAPD) as the material of choice for endodontic treatment of primary teeth until 2008. However, this material is not considered biocompatible because it causes an inflammatory reaction in periapical tissues and promotes slow root resorption, which can damage the permanent successor ${ }^{18}$. Therefore, the AAPD started to recommend materials based on $\mathrm{Ca}(\mathrm{OH})_{2}$ and/or iodoform as an alternative to zinc oxide and eugenol.

Materials based on $\mathrm{Ca}(\mathrm{OH})_{2}$ are poorly soluble in water, requiring a longer time to be dissolved, and cause no damage when in contact with apical tissues. In addition, they are easy to apply and are resorbed faster than the roots of primary teeth. On the other hand, these materials have some undesirable properties such as low radiopacity and viscosity that require their combination with other compounds such as iodoform and/or zinc oxide ${ }^{19,20}$. In addition to the known good biomechanical qualities of the combination with iodoform or zinc oxide, those materials also showed good results in terms of radiopacity, homogeneity and apical sealing. In addition, the combination of iodoform with other materials such as $\mathrm{Ca}(\mathrm{OH})_{2}$ increases radiopacity ${ }^{21}$. Thus, Calen ${ }^{\circledR}$ combined with iodoform provided better results in objective and subjective analyses.

The combination of $\mathrm{Ca}(\mathrm{OH})_{2}, 2 \%$ chlorhexidine and zinc oxide (2: 1: 2 ratio) has been proposed in cases of dental trauma. This medication exhibits excellent antimicrobial activity, high remineralizing capacity and relative radiopacity, is inexpensive, and does not require periodic replacement 22 . Thus, this intracanal material may become a viable alternative for obturation of primary teeth and was therefore tested in this study. However, this material did not perform well in terms of the parameters studied. Further studies are necessary to test other properties.

The flow of filling material can influence homogeneity, particularly in the apical third of the root. A good material should allow easy filling of the entire root canal, reduc- 
ing the formation of bubbles and the possibility of unsealed parts. We believe that some of the materials tested do not have adequate flow as they received inadequate evaluations (score 2) in the apical third. Another explanation could be related to anatomical variations in the root canal, since bovine primary teeth were used. However, considering the similar root dentin morphology of bovine and human teeth, permitting similar penetration of the endodontic obturation material into the dentinal tubules ${ }^{23,24}$, we believe that the use of these teeth did not influence our results.

Finally, the large number of inadequate scores was a surprising finding, as we expected more adequate homogeneity and apical sealing because this was an in vitro study of anterior teeth. Thus, the working condition is better than in the oral cavity, facilitating endodontic treatment. We do not believe that the evaluations were flawed because the intra-examiner agreement was high and the micro-CT images confirmed the inadequate scores. Our hypothesis is that the images were acquired without superimposition of other structures as occurs in clinical studies in which maxillary bones could mask bubbles or other failures. Therefore, the evaluations would favor to identify the irregularities in the homogeneity and apical sealing. However, it is also important to remember that the success rates of endodontic treatment in primary teeth do not only depend on a complete seal, but also on a set of clinical factors such as correct diagnosis, adequate chemical-mechanical root canal preparation, use of materials with desirable and biological properties, and an adequate coronal seal.

The results of the present study suggest that direct digital systems with higher resolution should be preferred for quality assessment of endodontic treatment in primary teeth since they improve the analysis of apical sealing.

\section{ACKNOWLEDGMENTS}

This work was partially supported by PIBIC-CNPq. The authors declare no conflict of interest.

\section{REFERENCES}

1. Seale NS. Indirect pulp therapy: an alternative to pulpotomy in primary teeth. Tex Dent J. 2010 Nov; $127(11): 1175-83$

2. Akbar I. Radiographic study of the problems and failures of endodontic treatment. Int J Health Sci. 2015 Apr;9(2):111-8.

3. Udupa H, Mah P, Dove SB, McDavid WD. Evaluation of image quality parameters of representative intraoral digital radiographic systems. Oral Surg Oral Med Oral Pathol Oral Radiol. 2013 Dec;116(6):774-83. doi: 10.1016/j.0000.2013.08.019.

4. Pontual AA, de Melo DP, de Almeida SM, Boscolo FN, Haiter Neto F. Comparison of digital systems and conventional dental film for the detection of approximal enamel caries. Dentomaxillofac Radiol. 2010 Oct;39(7):431-6. doi: 10.1259/dmfr/94985823.

5. Abesi F, Mirshekar A, Moudi E, Seyedmajidi M, Haghanifar S, Haghighat N, et al. Diagnostic accuracy of digital and conventional radiography in the detection of non-cavitated approximal dental caries. Iran J Radiol. 2012 Mar;9(1):17-21. doi: 10.5812/iranjradiol.6747. Epub 2012 Mar 25. 
6. Özen T, Kamburoglu K, Cebeci AR, Yuksel SP, Paksoy CS. Interpretation of chemically created periapical lesions using 2 different dental cone-beam computerized tomography units, an intraoral digital sensor, and conventional film. Oral Surg Oral Med Oral Pathol Oral Radiol Endod. 2009 Mar;107(3):426-32. doi: 10.1016/j.tripleo.2008.08.017.

7. Sögur E, Baksi BG, Grondahl HG, Lomcali G, Sen BH. Detectability of chemically induced periapical lesions by limited cone beam computed tomography, intra-oral digital and conventional film radiography. Dentomaxillofac Radiol. 2009 Oct;38(7):458-64. doi: 10.1259/dmfr/15206149.

8. Shintaku WH, Venturin JS, Noujeim M, Dove SB. Comparison between intraoral indirect and conventional film-based imaging for the detection of dental root fractures: an ex vivo study. Dent Traumatol. 2013 Dec;29(6):445-9. doi: 10.1111/edt.12041

9. Nascimento HA, Neves FS, de-Azevedo-Vaz SL, Duque TM, Ambrosano GM, Freitas DQ. Impact of root fillings and posts on the diagnostic ability of three intra-oral digital radiographic systems in detecting vertical root fractures. Int Endod J. 2015 Sep;48(9):864-71. doi: 10.1111/iej.12382.

10. Ramos Brito AC, Verner FS, Junqueira RB, Yamasaki MC, Queiroz PM, Freitas DQ, et al. Detection of Fractured Endodontic Instruments in Root Canals: Comparison between Different Digital Radiography Systems and Cone-beam Computed Tomography. J Endod. 2017 Apr;43(4):544-9. doi: 10.1016/j.joen.2016.11.017.

11. Pascon FM, Kantovitz KR, Puppin-Rontani RM. Influence of cleansers and irrigation methods on primary and permanent root. dentin permeability: a literature review. Braz J Oral Sci. 2006;5(18):1063-9. doi: 10.20396/bjos.v5i18.8641897.

12. Pinheiro SL, Araujo G, Bincelli I, Cunha R, Bueno C. Evaluation of cleaning capacity and instrumentation time of manual, hybrid and rotary instrumentation techniques in primary molars. Int Endod J. 2012;45(4):379-85. doi: 10.1111/j.1365-2591.2011.01987.x.

13. Farman AG, Farman TT. A comparison of 18 different $X$-ray detectors currently used in dentistry. Oral Surg Oral Med Oral Pathol Oral Radiol Endod. 2005 Apr;99(4):485-9.

14. Nascimento HA, Visconti MA, Ferreira LM, Suarez MA, Haiter Neto F, Freitas DQ. Effect of delayed scanning on imaging and on the diagnostic accuracy of vertical root fractures in two photostimulable phosphor plates digital systems. Int Endod J. 2016 Oct;49(10):973-9. doi: 10.1111/iej.12547.

15. Vasconcelos TV, Santaella GM, Nascimento HA, Rovaris K, Ambrosano GM, Freitas DQ. Digital radiographs displayed on different devices: effect on the detection of vertical root fractures. Int Endod J. 2016;49(4):386-92. doi: 10.1111/iej.12466.

16. Gupta S, Das G. Clinical and radiographic evaluation of zinc oxide eugenol and metapex in root canal treatment of primary teeth. J Indian Soc Pedod Prev Dent. 2011 Jul-Sep;29(3):222-8. doi: 10.4103/0970-4388.85829.

17. Navit S, Jaiswal N, Khan SA et al. Antimicrobial Efficacy of Contemporary Obturating Materials used in Primary Teeth- An In-vitro Study. J Clin Diagn Res. 2016;10(9):ZC09-ZC12.

18. American Academy on Pediatric Dentistry Clinical Affairs Committee. Guideline on Pulp Therapy for Primary and Immature Permanent Teeth. Pediatr Dent. 2016 Oct;38(6):280-8.

19. Silva LA, Leonardo MR, Oliveira DS, Silva RA, Queiroz AM, Hernández PG, et al. Histopathological evaluation of root canal filling materials for primary teeth. Braz Dent J. 2010 Jan;21(1):38-45.

20. Pramila R, Muthu MS, Deepa G, Farzan JM, Rodrigues SJ. Pulpectomies in primary mandibular molars: a comparison of outcomes using three root filling materials. Int Endod J. 2016 May;49(5):413-21. doi: 10.1111/iej.12478.

21. Ordinola-Zapata R, Bramante CM, García-Godoy F, Moldauer BI, Gagliardi Minotti P, Tercília Grizzo $\mathrm{L}$, et al. The effect of radiopacifiers agents on $\mathrm{pH}$, calcium release, radiopacity, and antimicrobial properties of different calcium hydroxide dressings. Microsc Res Tech. 2015 Jul;78(7):620-5. doi: 10.1002/jemt.22521. 
22. de Jesus Soares A, Yuri Nagata J, Casarin RC, Almeida JFA, Gomes BP, Augusto Zaia A, et al. Apexification with a new intra-canal medicament: a multidisciplinary case report. Iran J Radiol. 2012;7(3):165-70.

23. Costa BM, Iwamoto AS, Puppin-Rontani RM, Pascon FM. Comparative Analysis of Root Dentin Morphology and Structure of Human Versus Bovine Primary Teeth. Microsc Microanal. 2015 Jun;21(3):689-94. doi: 10.1017/S1431927615000434.

24. Xavier SR, Pilownic KJ, Gastmann AH, Echeverria MS, Romano AR, Geraldo Pappen F. Bovine Tooth Discoloration Induced by Endodontic Filling Materials for Primary Teeth. Int J Dent. 2017;2017:7401962. doi: 10.1155/2017/7401962. 